\title{
Research on Network Financial Data Analysis System
}

\author{
GuoTanxin \\ Department of Finance Management, Department of Management and Economics, Tianjin \\ University, Tianjin, 300072, China
}

Keywords: Network finance; data analysis system; design

\begin{abstract}
With the continuous development of social and economic, the role and impact of the financial industry in the whole economic system have gradually been people's attention. The financial industry can help the circulation of social funds, resulting in more economic benefits, which also has a reasonable regulatory role for the entire economic system. Internet technology has brought unprecedented opportunities and challenges to the financial industry. From the financial data analysis point of view, the number of network financial data is more difficult to analyze. Therefore, this paper starts with the concept of network financial data analysis, explores the design and operation of network financial data analysis system, hoping to bring reference to the financial industry.
\end{abstract}

\section{Introduction}

In the traditional financial industry, financial institutions according to business development and customer needs, through fixed computing methods or some specific procedures to do the relevant analysis activities.Financial data and the general data are significantly different, financial data has a greater impact for the entire national economy, and the financial data is more complex.The purpose of financial data processing is to get the results of the data calculation, to make basic construction for the financial institutions of the next step in the strategic plan, and make accurate forecast of the development trend.The traditional financial data analysis only deals with the more obvious data, but it cannot pay enough attention to the data with hidden value. The following table is a way of analyzing the traditional data of a financial institution and determining whether to grant the relevant borrowing business according to the profit and loss of the enterprise.

Table1 the financial institutions only make simple statistics and analysis for the enterprise's earnings and profits

\begin{tabular}{|l|c|}
\hline \multicolumn{1}{|c|}{ Item } & Money (yuan) \\
\hline Net sales revenue & $40,650,000$ \\
\hline Reduce: Cost of sales & $36,700,000$ \\
\hline \multicolumn{1}{|c|}{ Product sales profit } & $39,500,000$ \\
\hline Plus: Other business profits & 100,000 \\
\hline Reduce: Management costs & $1,200,000$ \\
\hline \multicolumn{1}{|c|}{ Financial expenses } & $1,500,000$ \\
\hline Operating profit & $1,350,000$ \\
\hline Reduce: Income tax & 450,000 \\
\hline Profit after tax & 900,000 \\
\hline
\end{tabular}

As shown in the Table 1, the financial institutions only make simple statistics and analysis for the enterprise's earnings and profits, don't make reasonable assessment for its development and credit rating, the reference value is not high. Therefore, the traditional financial data analysis model will soon be replaced by a new data analysis system. Network financial data that is mainly derived from the network financial business. Compared with the traditional financial data, network financial data has a wide coverage. Therefore, the analysis of network financial data requires a faster and more rigorous calculation.

China's online financial data analysis of the introduction of time is not too long, mainly 
concentrated in the past five years. In recent years, the Internet financial business achieve a huge leap, electronic payment, online banking, Internet lending and other Internet financial business was born, which not only facilitate the people's life, but also promote China's economic and financial development. Internet financial data analysis aims to provide services for financial institutions and users, to provide investment and financial management, risk control and other of the proposal, there is a strong practicality. With the development of network financial data analysis, the current data analysis work put forward new requirements.

\section{Storage space is larger.}

Network financial business because of its convenience has been sought after different groups of society. The greater the data covered by the network's financial business, the more storage space is needed. Related financial institutions want to make an accurate analysis, first of all to expand their own data storage space in order to do the next financial analysis of the basic work.

\section{Scope of analysis is extensive.}

In the past, the traditional financial data analysis business make analysis of a period of time data, but the Internet era, the higher the user coverage, the scope of its business analysis more widely. Advanced domestic and international economic environment is changing at any time, so the analysis of the entire financial environment data is also particularly important. In the future, the data analysis business of financial institutions will no longer be the "rich" demand, the family and individuals in the future for the financial data analysis needs will surge, financial institutions should see the situation, for each user to provide more accurate service.

\section{The plight of China's traditional financial data analysis}

\section{Data analysis is shallow}

The traditional financial data analysis method makes a simple analysis and processing for the special data, which cannot be a deeper level of data mining. The accumulation of financial data is huge, its potential economic value is deep, the financial market control has a very important reference value. Therefore, the traditional financial data analysis of the data for the shallow analysis has been unable to meet the needs of today's financial environment.

\section{Efficiency of manual analysis is slow}

Traditional financial data analysis is mostly artificial analysis; it hires a professional financial data analyst to make professional treatment. The advantage of this analysis is that the results are accurate and that the analyst can make one-on-one guidance and advice on the user, but the disadvantage is that the labor cost is high and the efficiency of the analysis is slow. Now the changes in online financial data are relatively fast, the results of analysts may soon be no longer adapt to the latest situation, so the prediction of the financial sector becomes no longer reliable.

\section{Lack of a complete financial data analysis system}

China's financial institutions achieve a faster pace of development; China's socialist market economic system has made a significant contribution. But in the field of financial data analysis business, it has not yet established a complete financial data analysis system. Financial institutions often look at immediate interests; do not focus on long-term development, not yet aware of the financial data analysis system for institutional development and business development importance. With the change of China's economic environment, network financial data will become a hot project in the future, financial institutions want to maintain long-term development and improve its core competitiveness, we must establish a sound financial data analysis system, especially the Internet financial data analysis, we should learn to break the routine, based on the overall situation, make the entire financial market rules and patterns in their own hands.

\section{The construction of network financial data analysis system}

\section{Network financial data genetic algorithm analysis system}

Network financial information data is large and complex; it requires the guidance of advanced theory to complete the relevant calculation and analysis. Genetic algorithm is widely used in the 
industry, it originated in the seventies of the last century, the theory of inspiration from the geneticist Darwin on biological genetic point of view to discuss, it can effectively maintain the biological population of outstanding genes can continue to eliminate the incompatible part of the environment.

In the field of financial analysis, genetic algorithm can help people make the data statistics and screening; data results have a certain degree of reliability. Especially in the financial risk control, the genetic algorithm can accurately evaluate the financial market risk forecast and economic development trend. Therefore, genetic algorithms have a place in the field of financial data analysis.

In the analysis of network financial data, genetic algorithm can also play its unique effect.Genetic algorithm can simulate the genetic law of nature, develop a special programming mode, and form a "data population", through the fitness function value to the corresponding assessment, the data according to programming Internal cross and calculation, making the excellent "population" to consider breeding and then expand. According to the genetic algorithm, a specific analysis of the domestic Internet financial platform data is as follows.

Table 2 a specific analysis of the domestic Internet financial platform data

\begin{tabular}{|l|l|l|l|l|}
\hline Month & Registered User & $\begin{array}{l}\text { Effective } \\
\text { number }\end{array}$ & Lost number & $\begin{array}{l}\text { total amount to } \\
\text { be received }\end{array}$ \\
\hline 5 & 100 & 59 & 17 & 715 \\
\hline 6 & 97 & 50 & 20 & 268 \\
\hline 7 & 174 & 108 & 32 & 598 \\
\hline 8 & 130 & 54 & 9 & 171 \\
\hline 9 & 113 & 31 & 3 & 94 \\
\hline 10 & 59 & 3 & 0 & 7 \\
\hline
\end{tabular}

From the above table 2 data can be seen, the platform of internal business and user traffic have a certain degree of decline, especially in terms of user traffic.the borrowing user groups are relatively more concentrated in a class, it is recommended that the small short-term investment is more insurance. All in all, the platform of the investment risk is relatively large, users need to be cautious. Through a similar data analysis model, the risk can be effectively controlled to further improve the accuracy of financial decision-making.

\section{Network financial data ant colony algorithm analysis system}

Ant colony algorithm is also a kind of scheme optimization mode which is inspired by nature. Ant colony algorithm was born in the nineties of last century, when the ant group is eating out from the nest to the location of the food, there are numerous paths to choose from, through the different ants for the path of perception, you can find the shortest path, and an important information quickly extended to the entire ant colony.Ant colony algorithm has a great role in the financial institutions in the process of network financial analysis, you can choose to first create a blank path, and then randomly select a path as the initial solution. At present, the ant colony algorithm has a better application effect for commercial banks to avoid financial risks. It can help commercial banks in the relevant financial activities to choose the best solution to enhance the accuracy rate, improve the speed of calculation and analysis, so as to achieve better data analysis results.

\section{Network financial data mining analysis system}

Data mining theory and technology are put forward in the nineties of last century, it has a prominent role for the effective processing of data and foreground prediction. Data warehouse is the basis of data mining technology. Financial institutions need to establish a sound data warehouse, including the user's information and institutions since the operation of the book financial data information, as well as national policy and financial environment changes and so on. Financial institutions can set a financial cycle, such as a month or a quarter, the database for timely updates and finishing, which play a groundbreaking significance in data mining analysis.

The biggest advantage of the data mining system is that it helps people discover the value of potential data from complex data and provide them with the awareness of the importance of potential data to help them with some of the relevant financial business options. In the specific practice, the data mining analysis system can help financial institutions to carry out detailed 
division of the user market, such as from age, income, place of residence, consumption level and other factors to distinguish. The institutions can be based on the results of the analysis system for this part of the customer group's targeted business docking. According to the data mining system design, a bank user is analyzed by the following.

Table 3 a bank user is analyzed

\begin{tabular}{|l|l|l|l|l|}
\hline Clustering & current balance $(+)$ & current balance(-) & average value & Standard deviation \\
\hline 1 & 145 & 0 & 24445.5 & 73408.73 \\
\hline 2 & 69 & 0 & 29164.41 & 78077.97 \\
\hline 3 & 133 & 0 & 152882.48 & 604633.58 \\
\hline 4 & 6182 & 1 & 5571.17 & 23957.76 \\
\hline 5 & 1985 & 0 & 22102.61 & 64825.42 \\
\hline 6 & 119 & 94 & 8432.82 & 18680.66 \\
\hline 7 & 46 & 0 & 2093.91 & 5798.48 \\
\hline 8 & 380 & 66 & 7729.67 & 33233.11 \\
\hline 9 & 0 & 413 & -24728.68 & 61844.23 \\
\hline 10 & 368 & 0 & 36264.24 & 93389.14 \\
\hline
\end{tabular}

\begin{tabular}{c|c|c|c|c|c|c|c|c|c|c|c|c|c|c|c|c|}
\hline$U$ & $A_{1}$ & $A_{2}$ & $A_{3}$ & $A_{4}$ & $A_{5}$ & $A_{6}$ & $A_{7}$ & $A_{8}$ & $A_{9}$ & $A_{10}$ & $A_{11}$ & $A_{12}$ & $A_{13}$ & $A_{14}$ & $A_{15}$ & $D$ \\
\hline 1 & $\mathrm{a}$ & 31.83 & 0 & $\mathrm{y}$ & $\mathrm{p}$ & $\mathrm{q}$ & $\mathrm{h}$ & 1.15 & $\mathrm{f}$ & $\mathrm{f}$ & 02 & $\mathrm{t}$ & $\mathrm{s}$ & 00212 & 0 & + \\
\hline 2 & $\mathrm{~b}$ & 59.67 & 4.56 & $\mathrm{y}$ & $\mathrm{p}$ & $\mathrm{w}$ & $\mathrm{v}$ & 3.14 & $\mathrm{f}$ & $\mathrm{f}$ & 07 & $\mathrm{t}$ & $\mathrm{s}$ & 00044 & 570 & + \\
\hline 3 & $\mathrm{a}$ & 25.50 & 0.51 & $\mathrm{y}$ & $\mathrm{p}$ & $\mathrm{w}$ & $\mathrm{v}$ & 1.6 & $\mathrm{f}$ & $\mathrm{t}$ & 0 & $\mathrm{t}$ & $\mathrm{s}$ & 00270 & 834 & + \\
\hline 4 & $\mathrm{a}$ & 26.83 & 1.53 & $\mathrm{y}$ & $\mathrm{p}$ & $\mathrm{q}$ & $\mathrm{h}$ & 3.65 & $\mathrm{f}$ & $\mathrm{f}$ & 06 & $\mathrm{f}$ & $\mathrm{s}$ & 00110 & 4 & + \\
\hline 5 & $\mathrm{a}$ & 21.17 & 5.615 & $\mathrm{y}$ & $\mathrm{p}$ & $\mathrm{w}$ & $\mathrm{h}$ & 1.81 & $\mathrm{f}$ & $\mathrm{f}$ & 0 & $\mathrm{f}$ & $\mathrm{g}$ & 00130 & 0 & + \\
\hline 6 & $\mathrm{a}$ & 34.33 & 7.4 & $\mathrm{y}$ & $\mathrm{p}$ & $\mathrm{q}$ & $\mathrm{bb}$ & 1.595 & $\mathrm{f}$ & $\mathrm{t}$ & 0 & $\mathrm{f}$ & $\mathrm{g}$ & 00410 & 0 & - \\
\hline 7 & $\mathrm{a}$ & 32.83 & 5 & $\mathrm{y}$ & $\mathrm{p}$ & $\mathrm{w}$ & $\mathrm{bb}$ & 13.5 & $\mathrm{f}$ & $\mathrm{t}$ & 0 & $\mathrm{f}$ & $\mathrm{s}$ & $?$ & 0 & - \\
\hline 8 & $\mathrm{~b}$ & 36.58 & 6 & $\mathrm{y}$ & $\mathrm{p}$ & $\mathrm{q}$ & $\mathrm{h}$ & 13.6 & $\mathrm{f}$ & $\mathrm{t}$ & 0 & $\mathrm{f}$ & $\mathrm{s}$ & 00970 & 0 & - \\
\hline 9 & $\mathrm{a}$ & 43.25 & 0.6 & $\mathrm{y}$ & $\mathrm{p}$ & $\mathrm{q}$ & $\mathrm{h}$ & 10.65 & $\mathrm{f}$ & $\mathrm{t}$ & 0 & $\mathrm{t}$ & $\mathrm{g}$ & 00410 & 0 & - \\
\hline 10 & $\mathrm{a}$ & 43.83 & 8 & $\mathrm{u}$ & $\mathrm{g}$ & $\mathrm{w}$ & $\mathrm{h}$ & 1.635 & $\mathrm{t}$ & $\mathrm{t}$ & 0 & $\mathrm{t}$ & $\mathrm{s}$ & 00170 & 3 & - \\
\hline
\end{tabular}

The above figure selects the bank original data of a certain stage, chooses 3 as the main operation group, calculates according to the maximum and minimum method, obtains the following formula, then carries on the discrete operation, and obtains the discrete three groups of data:

$F\left(X_{\sigma}\right)=3\left(t_{1}-0.125\right)^{2}+9\left(t_{1}-0.167\right)^{2}+3\left(t_{1}-0.2\right)^{2}+\left(t_{1}-0.25\right)^{2}+\left(t_{1}-0.285\right)^{2}+3\left(t_{1}-0.333\right)^{2}$
$+\left(t_{1}-0.4\right)^{2}+3\left(t_{1}-0.142\right)^{2}+\left(t_{2}-0.625\right)^{2}+3\left(t_{2}-0.75\right)^{2}+\left(t_{3}-0.714\right)^{2}+\ldots+3\left(t_{3}-0.833\right)^{2}+$
$3\left(t_{3}-0.857\right)^{2}+3\left(t_{4}-0.5\right)^{2}+\left(t_{4}-0.875\right)^{2}+6\left(t_{5}-1\right)^{2}$
\begin{tabular}{|c|c|c|c|c|c|c|c|c|c|c|c|c|c|c|c|c|}
\hline$U$ & $A_{1}$ & $A_{2}$ & $A_{3}$ & $A_{4}$ & $A_{5}$ & $A_{6}$ & $A_{7}$ & $A_{8}$ & $A_{9}$ & $A_{10}$ & $A_{11}$ & $A_{12}$ & $A_{13}$ & $A_{14}$ & $A_{15}$ & $D$ \\
\hline 1 & 1 & 2 & 1 & 1 & 1 & 1 & 1 & 1 & 1 & 1 & 1 & 2 & 1 & 2 & 2 & 2 \\
\hline 2 & 2 & 3 & 1 & 1 & 1 & 2 & 2 & 2 & 1 & 1 & 2 & 2 & 1 & 1 & 2 & 2 \\
\hline 3 & 2 & 1 & 1 & 1 & 1 & 2 & 2 & 1 & 1 & 2 & 2 & 2 & 1 & 3 & 2 & 2 \\
\hline 4 & 1 & 1 & 1 & 1 & 1 & 1 & 1 & 2 & 1 & 1 & 1 & 2 & 1 & 1 & 2 & 2 \\
\hline 5 & 1 & 1 & 2 & 1 & 1 & 2 & 1 & 1 & 1 & 2 & 1 & 2 & 1 & 2 & 2 & 2 \\
\hline 6 & 1 & 2 & 2 & 1 & 1 & 1 & 3 & 1 & 1 & 2 & 1 & 1 & 2 & 4 & 1 & 1 \\
\hline 7 & 1 & 2 & 1 & 1 & 1 & 2 & 3 & 3 & 1 & 2 & 1 & 1 & 1 & 1 & 1 & 1 \\
\hline 8 & 2 & 2 & 1 & 1 & 1 & 1 & 1 & 3 & 1 & 2 & 1 & 1 & 1 & 4 & 1 & 1 \\
\hline 9 & 1 & 3 & 1 & 1 & 1 & 1 & 1 & 3 & 1 & 2 & 1 & 2 & 2 & 4 & 1 & 1 \\
\hline 10 & 1 & 3 & 2 & 2 & 2 & 2 & 1 & 1 & 2 & 2 & 1 & 2 & 1 & 2 & 2 & 1 \\
\hline
\end{tabular}

The improved ant colony algorithm can help financial institutions to find the latest financial information from discrete forms and make accurate estimates of the three groups' ability to invest in risk. From the above table we can see that the current balance of the redlist 3 is positive and the current balance is more than about 150,000 . Therefore, the potential investment ability of the cluster 3 group can be found. The more the balance, the higher the amount of the user's deposit, Or the higher the total income level, then the higher the possibility of investment. Financial institutions can be based on the excavation of the data, the cluster 3 customer group design-related financial services portfolio, so as to develop the business. In addition, the clustering of the customer group is negative, the balance is negative, so this part of the customer groups are mostly less deposits, 
speculative high customer base. In the case of financial environment is not stable, the customer group and financial institutions are not recommended to make the relevant investment initiatives.

Network financial data artificial analysis and intelligent analysis integration system

In the field of traditional financial data analysis, a professional data analyst need carry out related work. In the new period, the financial institutions can not erase the existence of professional staff rationality. In the entire electronic operation of the financial data analysis system, it can also play the role of artificial analysis. Intelligent analysis can improve the analysis and operation speedto provide the relevant optimization programfor the general financial activities. The data is the digital projection of the objective world. Whether this projection is accurate depends on how we collect, acquire, and organize the data, the frequency and the dimension. The vast majority of algorithms and models are only the result of formal recognition of human understanding and insight.

\section{Conclusion}

Computing power and the development of intelligent technology provide people with better data collation. Regardless of P2P loan data, or network credit data, it is difficult to believe that their volume can be how much, which can be stained with the so-called large data, and then need to use large data technology.

Most of the Internet financial companies are still small, the user size and transaction volume are not large, but also unable to bear the large data infrastructure and processing costs. To P2P lending industry for example, whether it is dependent on the network audit or offline audit, the loan officer's experience and due diligence are far more important than the big data, the cost is more savings. At present, the trend of $\mathrm{O} 2 \mathrm{O}$ in $\mathrm{P} 2 \mathrm{P}$ industry shows that the importance of offline work is far more than pure data analysis in China's specific credit and data environment. Therefore, after the system is designed, it should be used in conjunction with traditional methods, such as the initial screening, inspection and return of borrowers based on these data, rather than only superstition data.

\section{References}

[1] $\mathrm{Yu}$ Chun. Data mining technology based on financial data analysis system design and implementation [D]. Electronic Science and Technology University .2014

[2] Tang Li. Financial data for high efficiency data processing mechanism research and design [D]. Beijing University of Posts and Telecommunications .2015

[3] Lan Qiujun. Financial time series implicit mode mining method and its application [D]. Hunan University .2005

[4] Feng Wei.Study and Implementation of Massive Data Analysis System Based on Cloud Computing [J]; Journal of Shanghai Jiaotong University; 